open and the head flexed the cesophagus is straightened (Starling); but, after the tube has passed into the osophagus, the assistant holding the head should be instructed to keep the chin up, as with the head in the extended position there is less chance of any regurgitating food entering the mouth.

In a strong patient, should food regurgitate into the mouth, mere pinching of the tube by the operator until the contents of the mouth have been swallowed is sufficient ; but, should the same circumstance arise in a feeble subject, it is safer to withdraw the tube, at the same time elevating the patient to a sitting posture before again passing the instrument.

In order to prevent the patient voluntarily ejecting the food by the contraction of his abdominal muscles, the operator, or an assistant, should apply the palm of his hand to the patient's epigastric region while the muscles are still flaccid, and exert just sufficient pressure to prevent their contraction. This mancuvre is, as a rule, successful in women and in the majority of men, unless the latter be possessed of an exceptional muscular development.

In vomiting and regurgitation due to reflex causes, gastric lavage with a weak solution of Condy's fluid, or with a solution of bicarbonate of soda (one drachm to the pint), about half an hour before feeding, gives the most satisfactory results.

\title{
BIFIDITY OF THE SPINOUS PROCESSES OF VERTEBRA.
}

By P. Campbel. Smith, L.R.C.P.

Dr. Ch. Féré has done me the honour of asking me to publish an observation to which I drew his attention some months ago, and which he has confirmed-the occurrence in degenerates of bifidity of one or more spinous processes, especially of the lumbar vertebræ. Since receiving my letter Dr. Féré has seen a dozen cases, of which eight were in the lumbar region; they were associated with a certain degree of hypertrichosis, which he has described (1) as "the faun's tail." One of his patients was a neurasthenic, the remainder were insane. In a period of several years I have met with hardly as many cases as Dr. Féré has seen in a few months; but he has many more degenerates under observation than fall to my lot. None of my cases have been accompanied by hypertrichosis. One of them was in the dorsal spine, the remainder in the lumbar, and especially the lower lumbar. In most instances one vertebra only showed the condition; sometimes two or even three were affected, and these were always adjacent, except in one case where two contiguous spinous processes and one at some distance were bifid, all these being in the dorsal region. About half the patients were insane, the remainder, if remember rightly, being all more or less neurasthenic. I do not think that any conclusion can be drawn from Dr. Féré's figures and my own as to the proportion of cases occurring in the sane and the insane respectively, but $I$ have no doubt that, like other signs of degeneracy, the condition occurs most frequently in the insane. As to its association with neurasthenia, I have already stated $\left({ }^{2}\right)$ my belief that neurasthenia is a congenital state, and there are grounds for holding that it is itself a stigma of degeneracy.

In his letter to me M. Féré refers to the best position for investigating this condition. I have usually examined my patients while they were sitting up in bedan attitude that involves some flexion of the trunk-and have trusted rather to palpation than to inspection in the first instance. Dr. Féré has adopted the plan of placing the patient on his side with his trunk flexed.

(1) La Famille Névropathique, 2me ed., p. 274 et fig. 13.-(') Brit. Med. Fourn., 1903, vol. i, p. 78I.

\section{A NEW SAFETY BATH TAP.}

Considerable attention has been paid to the construction and fittings of baths, lavatories, etc., for public institutions, the general principles adopted being simplicity of action and safety from accidents. It is certainly an advantage to be able 
to deliver warm water at the temperature desired by the turning of one tap. The ordinary fittings which can only command hot or cold water are out of date. The latest patent is submitted, under the name of Murray's Anti-scalding Tap, by Messrs. A. Liggatt and Co., Ltd., Caledonian Brass Works, Barrhead. It deserves the special attention of those who are responsible for the safety of persons who are unable to exercise ordinary precautions in their daily life, as well as those who use spray or needle baths as ordinary householders. The upper part of the tap contains an ingenious arrangement of toothed wheels, one of which comes into action before the other by an ingenious and simple device. These are actuated by $a$ detachable key which is fitted in a slot, turning one quarter of a revolution for cold water; on withdrawal and reinsertion another quarter of a revolution for tepid water; and after another withdrawal and reinsertion still another quarter of a revolution for hot water. If the cold water be shut off the first manceuvre shows that it has been disconnected, and thereby calls the attention of the person using the tap to the fact. The temperature of the water can be adjusted to a nicety, according to the supply, and a bath can be filled in thirty-five seconds at any ordinary pressure. In a mixing box below the mechanical parts are two screw down valves, moving on right and left hand screws respectively. By these arrangements the cold water is first delivered and finally stopped, as the valve is double-seated-above and below, and by the gradual revolution of the toothed wheels the hot water valve is gradually opened while the cold water valve is gradually closed. Of course by this arrangement the cold water is turned on first and the hot water is turned off first. Inasmuch as the desired temperature of water flowing into the bath or basin can be accurately adjusted, there is no temptation to use the hot water unmixed. An arrow head on the spindle shows exactly how the tap is working-for the delivery of cold, tepid, or hot water. It should be added that the construction of the mixing box is simple, and admits of easy access to the valves when it is necessary to replace the washers.

\section{INTERNATIONAL CONGRESS ON THE CARE OF THE INSANE.}

An International Congress on the care of the insane (Congresso internazionale dell' assisteuza degli alienati) will be held at Milan from September 26th to the 3oth, 1906. The work of the Congress will deal especially with the family treatment (boarding out, etc.) of the insane; but will cover such questions as the construction, organisation, direction, and administration of asylums for the insane; of special wards for observation and supervision; and of agricultural colonies; the treatment of the feeble-minded, of epileptics, of alcoholics, of the pellagious, of chronic patients, of criminals, and of the morally insane, etc.; psychiatric dispensaries; the personnel of treatment (nurses, attendants, various assistants, etc.); legislation; etc., etc.

The President will be Prof. Tamburini, and the General Secretary Prof. Ferrari (Bertalia-Bologna).

A Committee has been formed for each country with the object of obtaining members and also communications on the subjects coming under the various headings detailed below.

The Committee for England consists of Dr. Outterson Wood, Dr. Percy Smith, Dr. Robert Jones, Dr. Mercier, Dr. Hubert Bond, and Dr. H. J. Macevoy.

The Committee for Scotland consists of Dr. Urquhart, Dr. Ford Robertson, and Dr. Ireland.

The arrangements for Ireland are in the hands of Dr. Conolly Norman.

Two general questions are to be treated by appointed delegates from each country represented at the Congress :

(I) The progress in the care of the insane, especially of family care, in various countries since 1902 (the date of the last Antwerp Congress) up to the present time.

(2) The organisation of wards for observation, supervision, and isolation in asylums and colonies. Means which have given the best results.

The other subjects and questions for discussion are- 